\title{
Chinese Minority Perceives the Doctor-Patient Relationship Differently: A Cultural and Economic Interpretation
}

\section{OPEN ACCESS}

Edited by:

Connie J. Evashwick,

George Washington University,

United States

Reviewed by:

Ranjeet Kumar Sinha,

Patna Medical College, India

Afolaranmi Olumide Tolulope,

Jos University Teaching Hospital, Nigeria

James W. Holsinger,

University of Kentucky, United States

*Correspondence:

Hengjin Dong donghj@zju.edu.cn

Specialty section:

This article was submitted to

Public Health Policy,

a section of the journal

Frontiers in Public Health

Received: 06 August 2019 Accepted: 24 October 2019 Published: 18 November 2019

Citation:

Yang $Q$, Zhang $H$, Yu M, Hu X, Gu Y, Sun $X$, Zhen $X$, Gu S, Huang $M$, Wei J,

Zeng $Y$ and Dong $H$ (2019) Chinese Minority Perceives the Doctor-Patient Relationship Differently: A Cultural and Economic Interpretation.

Front. Public Health 7:330.

doi: 10.3389/fpubh.2019.00330

\begin{abstract}
Qian Yang ${ }^{1,2}$, Hao Zhang ${ }^{3}$, Mengfei $\mathrm{Yu}^{1}$, Xiaoqian $\mathrm{Hu}^{1}$, Yuxuan $\mathrm{Gu}^{1}$, Xueshan Sun ${ }^{1}$, Xuemei Zhen ${ }^{1}$, Shuyan Gu $^{1}$, Minzhuo Huang ${ }^{1}$, Jingming Wei ${ }^{1}$, Yuhang Zeng ${ }^{1}$ and Hengjin Dong ${ }^{1,4 *}$

${ }^{1}$ Center for Health Policy Studies, School of Public Health, Zhejiang University School of Medicine, Hangzhou, China, ${ }^{2}$ Department of Social Medicine, School of Public Health, National Clinical Research Center for Child Health of The Children's Hospital, Zhejiang University School of Medicine, Hangzhou, China, ${ }^{3}$ School of Medicine, Hangzhou Normal University, Hangzhou, China, ${ }^{4}$ Department of Social Medicine, School of Public Health, The Fourth Affiliated Hospital Zhejiang University School of Medicine, Yiwu, China
\end{abstract}

In China, doctor-patient relationships (D-P relationships) are cited frequently and attracted international attention. This study assesses whether the D-P relationship experienced by the Chinese is associated with ethnicity, hospital hierarchies, and socioeconomic factors. In a national cross-sectional survey, multi-stage random sampling was adopted to assess regional and socio-economic differences between year 2016 and year 2017. Each area surveyed consisted of about 250 randomly chosen households, and valid results were obtained from 4,173 adults aged 16-99. When provided a choice of eight types of D-P relationship, for doctors in primary care institutions, $63.8 \%$ of ethnic minorities indicated having a friend-type relationship with their physicians, with $23.3 \%$ having a trading/reciprocal relationship. Han Chinese, however, predicts the opposite relationship between doctors from different hierarchy and the types of D-P relationship. For physicians working in hospitals, this difference in relationship was more pronounced, where 52.9\% of ethnic minorities indicated having a friend-type relationship with their physicians, and $30.1 \%$ indicated the presence of a trading/reciprocal relationship. For Han Chinese, however, 53.3\% indicated having a reciprocal relationship with their doctor. Overall, the prevalence of friendly D-P relationships was correlated with ethnic minorities, lower levels of education, and lower incomes. Ethnic minorities are most likely to perceive their physicians as friends, while Han Chinese are more likely to perceive a trading relationship with their physicians. The primary contribution of this research is the finding that D-P relationships differ for Han Chinese and other ethnic minorities.

Keywords: doctor-patient relationship, socioeconomic status, ethnic minorities, medical sociology, social change, hospital hierarchy

\section{INTRODUCTION}

Chinese doctor-patient relationships (D-P relationships) have been scrutinized intensely in recent years. Violence against doctors (VAD) has been frequently reported both domestically and abroad. $\mathrm{D}-\mathrm{P}$ relationships in China have been characterized by an increasing number of medical disputes and even outright violence $(1,2)$. A report published in 2015 by the Chinese Medical Doctor 
Association reported almost $60 \%$ of medical staff in China have experienced verbal abuse and around one in seven have been physically assaulted (3).

Traditionally, the Chinese have had more positive D$\mathrm{P}$ relationships. In ancient China, people greatly respected physicians. One story tells of a seriously ill duke two thousand years ago who asked for the services of a physician named Hwan. Before Hwan came, the duke dreamt that his disease turned into two boys, who said, "That is a skilled physician; it is feared he will hurt us; how shall we get out of his way?" Then, one of them said, "If we take our place above the heart and below the throat, what can he do to us?" When the physician arrived, he said, "Nothing can be done for this disease. Its seat is above the heart and below the throat. If I assail it with medicine, it will be of no use; if I attempt to puncture it, it cannot be reached. Nothing can be done for it." If this happened today, the physician might be attacked by a patient who values utility first and foremost. However, the duke said, "He is a skilled physician, to give him large gifts, and to send him back to his hometown" (4).

The correlation between D-P relationships and race or ethnicity is also a worldwide concern. A study comparing perceived D-P relationships among different ethnicities in Israel showed that Arabs more frequently chose the term "friend" to describe their current D-P relationship than Jews, and generally desired this friend relationship (5). While no study has been conducted on perceptions of D-P relationships in China, Chinese ethnic minorities have been found to have different cognition and behaviors than that of Han Chinese, including different cultural histories, ecologies (6), and health practices. For instance, Chinese ethnic minorities experience different medical resource distributions, health equity (7), and mental health prejudices (8). China officially recognizes 55 ethnic minority groups in addition to the Han majority (9). According to the sixth Census of Population, the Han population consisted of 1225.9 million people, accounting for $91.51 \%$; while the ethnic minority population consisted of 113.8 million people, and only $8.49 \%$ (10). Folk psychological studies have found that the ethnic minorities have more pronounced emotions than Han Chinese (11). In addition, ethnic minority students are more satisfied with neighborhood relationships than the Han Chinese (12).

While China was undergoing globalization, modernization and urbanization, the differences between the ethnic minorities and the Han Chinese were more pronounced. Before reform, China was characterized by collectivism and Confucian dynamics (13-15). Its predominant features were persistence (perseverance), personal steadiness (reliability), respect for tradition, and reciprocation (16). It has been argued that the transition to a market economy has led to the moral deterioration of Chinese citizens. The development of business ethics and professional morality has not kept pace with market reforms (17-19). Lack of professionalism within the Chinese health care system has also been considered one of the main problems resulting from marketing and medical reforms (20).

Conversely, it has been found that income has less impact on the well-being of ethnic minorities than that of the Han Chinese (11). It seems that Confucianism, which values respect for brotherhood, social harmony, and protection of the interests of one's in-group $(21,22)$, has been retained more strongly by ethnic minorities. One of the significant expressions of this trend in the Han Chinese is the loss of trust among interpersonal relationships that is vital to health care reform.

A discussion of Chinese relationships is critical to Chinese indigenous psychology. The representative theories of Chinese indigenous psychology are based mostly on a pattern of difference sequence $(23,24)$, which describes the essence of social structure and relationship in an earthbound community in China. Like the concentric waves that become bigger and bigger after a stone is thrown into the water, every person is in the center of his own circle, and his or her social relationships emanate outwards. The Chinese trust people closer to the center (self), like family and friends, and put less trust in people further away from them, such as customers or strangers. This may influence patients' attitudes toward their doctors based on which layer in which patients put their doctors. Because Chinese indigenous psychology has yet to provide an answer as to which layer this may be, we refer to western medical knowledge concerning D-P relationships.

Generally speaking, the D-P relationships have experienced three revolutions in western culture. Initially, in 1847, the American Medical Association Code of Medical Ethics called for "total patient obedience." Gradually, a respect for patient autonomy began to form (25). Until the D-P relationships were transformed from a traditional paternalistic style (26) to a buyer and seller relationship (27). For example, the Patient Protection and Affordable Care Act (also known as Obamacare) in the US referred to the "consumer" instead of the "patient" (28). However, this has been repudiated in a recent study (5), marking a third transformation. The World Health Organization (WHO) and its international declarations articulated people-centered healthcare approaches (29). These approaches advocate for the knowledge of a patient's value, and for "treating the whole patient," with attention to therapeutic relationships (30-33).

According to studies of D-P relationships in various cultures, D-P relationships can be described as client, customer, insured, partner, or friend relationships $(25,34-36)$. Given that friend is a term that infers trust, interest, and a more human connection, those who perceive that they have relationships similar to friendships with their doctors are more likely to have confidence in their treatment. In part, confidence in one's treatment is a measure of confidence and trust in one's physician. Studies of patient satisfaction show the importance of "being known," "having a human connection," and "being understood" as intrinsically valuable $(37,38)$.

The functions of hospitals and primary health institutions are different. Doctors in community centers have more primary care responsibilities, which include first-contact access for each new need, long-term person-focused care (as opposed to disease-focused), comprehensive care for most health needs, and coordinated care in referrals (39). The nature of primary care suggests that doctors who work in primary care institutions may differ from doctors who work in hospitals, in that they tend to have a pro-social orientation toward family and community (40). In contrast, Chinese public hospitals have faced policy and regulation problems because social responsibilities are unfunded 
and, thus, hospital directors are preoccupied with generating revenue from services and medicines to cover basic operational costs (41).

Based on these differences in the focus of hospitals and primary care institutions, D-P relationships also differ between hospitals and primary care institutions. Several studies have compared D-P relationship perspectives of Chinese medical staff in urban tertiary hospitals and primary care institutions. The results consistently showed that medical staff in higher-level hospitals scored lower on harmony of the D-P relationships, while doctors and nurses in primary care institutions gave higher scores (42-44).

This study tested this conclusion and the impact of ethnicity on the perception of D-P relationships by comparing two representative provinces in the eastern and western regions of China. These two regions were chosen because ethnic minorities are more concentrated in western China, with 46 ethnic minorities represented, while Han Chinese predominantly live in eastern regions. All five ethnic autonomous regions in the country are in the west, with an area of 5.95 million square kilometers, accounting for $85.95 \%$ of the western total area. According to the Confucian teaching, courtesy calls for help from the wild (礼失而求诸野) (45), the lesser impact of social transitions on minority groups may be the result of the preservation of traditional Chinese culture and values, including trust in and friendly perceptions of physicians. Thus, we surveyed residents both in Zhejiang and Qinghai to compare patient perspectives on D-P relationships in big hospitals and primary care health institutions.

\section{METHOD}

\section{Study Design and Participants}

This cross-sectional study is part of a national project studying referral systems. The survey assessed satisfaction with health care services and was composed of six parts: general family conditions, the individual conditions of family members, illnesses, and injuries occurring within the last 2 weeks, hospitalizations in the previous year, satisfaction with and accessibility of primary health care institutions, and willingness to receive health care services, with the latter being the focus of variable assessment in the survey section. Two provinces were selected as the main study sites: Zhejiang Province and Qinghai Province. Since 2016, Zhejiang and Qinghai provinces have been identified as the new medical health system reform pilot provinces by the National Health Commission of the PRC (the former National Health and Family Planning Commission), they play a demonstration effect in the exploration of medical and health system optimization and hierarchical diagnostic model. More importantly, Zhejiang Province is a wealthy eastern province neighboring Shanghai City, while Qinghai Province is an inner province of northwestern China. Thus, it has a much slower speed of globalization, modernization, and urbanization than Zhejiang province. Investigations were conducted during 2016 (GDP [in billions of $¥$ ] of Zhejiang: 4,725,136; Qinghai: 257.25) and 2017 (GDP of Zhejiang: 5,176,826; Qinghai: 262.48). The ethnic minority population in Qinghai province is $46.98 \%$, but in Zhejiang, there are only $2.23 \%$ (according to the latest census data of China). By choosing Qinghai and Zhejiang as the study sites, we could compare the ethnic minorities and Han Chinese conveniently.

The survey was conducted among the resident population in each region, including the residents moving to the area in the past 6 months and those living there for more than 6 months. The exclusion criteria were those under 16 years old and those could not response by themselves, such as those work outside of the county or district. Their data were reported by their parents. Thus, our data still covered the situation of all ages. According to principles of purposiveness, economic efficiency, and feasibility, the multi-stage probability sampling was used. In the first stage, Qinghai and Zhejiang provinces were selected. In the second stage, we have adopted the multistage clustered probability sampling frame. There are 33 counties in Zhejiang and 34 counties in Qinghai. After running a Q-cluster analysis method in terms of 10 socio-economic development indices and 5 key indicators of health system development, we have found that Zhejiang has 2 layers (developed and undeveloped), and Qinghai has 3 layers (developed, developing and undeveloped). Thus, in Zhejiang Province, the representative regions were Jiashan County (a developed region) and Jinyun County (an undeveloped region). In Qinghai Province, we sampled four counties or districts because the population density in Qinghai Province is much lower ( 8 persons $/ \mathrm{km}^{2}$ ) than in Zhejiang Province (533 persons $/ \mathrm{km}^{2}$ ) (46). We sampled Chengxi district of Xining city (developed), Ping'an district of Xining city Huzhu county (developing), and Jianzha county (undeveloped) in Qinghai. Names of the counties and number of households selected in both Provinces were in Table 1. In the third stage, Probability Proportionate to Size Sampling (PPS) was used in Qinghai province. The calculation indices that proportion of permanent resident, urban population and rural population in developed, developing and undeveloped layers were presented in Table 2. The calculation indices of Zhejiang province are the proportion of agricultural and non-agricultural population instead of the proportion of urban and rural population. Because as an eastern province, the rate of urbanization of Zhejiang is very fast. In recent years, many agricultural populations have been divided into urban population, and the living habits and health service utilization habits of farmers living in cities are obviously different from those of real urban population. Although, Zhejiang urban population accounted for $67 \%$, while the rural population accounted for $34 \%$, but in 2016, Zhejiang province town reduced to $67 \%$, which means, the non-agricultural population was only $32 \%$, while the agricultural population reached to $68 \%$. Therefore, the sampling according to the proportion of agricultural and non-agricultural population drawn with a more realistic representative than proportion of urban and rural population.

\section{Data Collection and Quality Control}

The data were collected by well-trained and qualified investigators through household survey and investigation. Investigators were recruited in the local study sites. They are young people with educational level equal or above high school. 
TABLE 1 | Sampling distribution of residents' health service utilization.

\begin{tabular}{|c|c|c|c|c|}
\hline Province & County name & Representative characteristic & Street/town name & Sample size (household) \\
\hline Zhejiang & Jiashan county & Developed & Luoxing street & 250 \\
\hline Zhejiang & Jiashan county & Developed & Yaozhuang town & 250 \\
\hline Zhejiang & Jinyun county & Undeveloped & Wuyun street & 250 \\
\hline Zhejiang & Jinyun county & Undeveloped & Xinjian street & 250 \\
\hline Qinghai & Chengxi district & Developed & Pengjia stockaded village & 276 \\
\hline Qinghai & Ping'an district & Developing & Ping'an town & 100 \\
\hline Qinghai & Huzhu county & Developing & Donggou town & 124 \\
\hline Qinghai & Jianzha county & Undeveloped & Cuozhou town & 100 \\
\hline
\end{tabular}

TABLE 2 | The percentage of population characteristic of sampling sites.

\begin{tabular}{|c|c|c|c|c|}
\hline $\begin{array}{l}\text { Population } \\
\text { characteristic }\end{array}$ & $\begin{array}{l}\text { Developed } \\
(\%)\end{array}$ & $\begin{array}{l}\text { Developing } \\
\text { (\%) }\end{array}$ & $\begin{array}{c}\text { Undeveloped } \\
(\%)\end{array}$ & Total (\%) \\
\hline \multicolumn{5}{|c|}{ The percentage of Qinghai resident's population } \\
\hline Permanent & 47.93 & 37.36 & 14.71 & 100.00 \\
\hline Urban & 33.06 & 12.31 & 4.41 & 49.78 \\
\hline Rural & 14.87 & 25.05 & 10.31 & 50.23 \\
\hline \multicolumn{5}{|c|}{ The percentage of Zhejiang resident's population } \\
\hline Permanent & 47.93 & - & 14.71 & 100.00 \\
\hline Non-agricultural & 26.87 & - & 4.93 & 31.80 \\
\hline Agricultural & 45.36 & - & 22.83 & 68.20 \\
\hline
\end{tabular}

The investigators inquired all household members in local language according to the questionnaire survey items. They conducted the investigation when they were off work or in the weekends.

The content of the questionnaire and survey process were optimized and modified after consulting health policy research experts, health administrators, and medical staff. Over the course of the investigation, the objectives were clarified, and the survey specifications altered accordingly. When participants raised questions, the investigators gave immediate feedback. The informed consent was obtained from the participants before the survey. Graduate students from Zhejiang University were responsible for the data quality. They investigated each site for quality control, verification, and re-examination (sampling) after the survey. They also checked and verified the errors and omissions in the questionnaires each day during the survey.

\section{Dependent Variables}

The indicators in this study are perceived D-P relationships in primary care institutions and perceived D-P relationships in big hospitals. The survey questions for each of these indicators were as follows.

$\rightarrow$ Perceived D-P Relationships in Primary Care Institutions: D$P$ relationships in primary care institutions are most similar to which of the following relationships? (1) parents and children, (2) teachers and students, (3) friends, (4) work partners, (5) comrades, (6) superiors and subordinates, (7) trading services/reciprocal, or (8) other. $\rightarrow$ Perceived D-P Relationships in Big Hospitals: D-P relationships in big hospitals are most similar to which of the following relationships? (1) parents and children, (2) teachers and students, (3) friends, (4) work partners, (5) comrades, (6) superiors and subordinates, (7) trading services/reciprocal, or (8) others.

\section{Key Independent Variables}

While we looked at individual and household social and economic characteristics (Table 4), the main independent variable we wanted to explore was ethnicity and the type of health care institution individuals sought first, which were assessed with the following questions.

Ethnic Nationality. "Please choose your ethnicity as below:" The top eight ethnicities found in the study areas were listed as the options: Han, Zhuang, Hui, Wei, Meng, Zang, Miao, and She. For analysis, ethnicity was dichotomized into Han Chinese and ethnic minority for simplicity. we coded the response of Han as "majority" and the rest as "ethnic minorities."

First Contact Health Institution. We asked which kind of health institution respondents usually contact first, including six types of health care institution: (1) township health center, (2) community health center, (3) county/city/district of the provincial-level health institutions, (4) municipality/area/municipal district health institutions, (5) province/autonomous region/municipality directly under the central government health institutions and above, (6) others. For analysis, we coded responses of 3-5 as "big hospital" (0), 1-2 as "primary care institutions" (1), and 6 as "others" (2).

\section{Statistical Analysis}

For statistical analysis, age was categorized into five groups: 1829, 30-39, 40-49, 50-64, and 65+. Education level was separated into eight levels. Relative income was dichotomized to average or below average and above average. Because the per capita income of Qinghai Province $($ Mean $=11,779 ¥, S D=24,454 ¥)$ is much lower than that of Zhejiang Province (Mean $=26,722 ¥$, $S D=21,625 ¥)$, we calculated the mean of the two provinces separately. Based on an initial review of the survey results that indicated relatively low proportions for six of the eight types of relationships, perceived D-P relationships were categorized 
TABLE 3 | Han and minority perceived D-P relationship in primary care institutions and large hospitals.

\begin{tabular}{|c|c|c|c|c|c|}
\hline & & Han $(n, \%)$ & Minority $(n, \%)$ & Total $(n, \%)$ & $p$-value \\
\hline \multirow[t]{4}{*}{ Primary care institutions } & Friend-type & 1,093 (29.4) & $293(63.8)$ & 1,386 (33.2) & \\
\hline & Trading/reciprocal-type & 1,470 (39.6) & 107 (23.3) & $1,577(37.8)$ & \\
\hline & Other-type & $1,151(40.0)$ & $59(12.9)$ & $1,210(29.0)$ & \\
\hline & Total & $3,714(100.0)$ & 459 (100.0) & $4,173(100.0)$ & $<0.001$ \\
\hline \multirow[t]{4}{*}{ Large hospitals } & Friend-type & 477 (12.8) & $243(52.9)$ & $720(17.3)$ & \\
\hline & Trading/reciprocal-type & $1,987(53.5)$ & $138(30.1)$ & $2,125(50.9)$ & \\
\hline & Other-type & $1,250(33.7)$ & $78(17.0)$ & 1,328 (31.8) & \\
\hline & Total & $3,714(100.0)$ & $459(100.0)$ & $4,173(100.0)$ & $<0.001$ \\
\hline
\end{tabular}

p-value compared with Han and Minority by $\chi^{2}$-test.

into friends, trading services, and other for doctors in primary care institutions and large hospitals. In accordance with social transition theory, the possible influence of ethnicity, the openness of different regions, and economic factors, which may have similarities to social transitions, have been controlled for their impact on the perception of D-P relationships. We also controlled the major demographics that may have confounding effects. Thus, the independent variables included ethnicity, province, income, education, sex, and age (Tables 5, 6). A potential interaction was also considered: between province and ethnicity.

A chi-square test was used to analyze the association between demographic characteristics and perceived D-P relationships. A $p<0.05$ was considered statistically significant. Population characteristics are described as percentage of the non-missing value. We also used a chi-square test to compare the difference of D-P relationships between Han Chinese and ethnic minorities according to different types of health care institutions (Table 3).

The dependent variable is the D-P relationships, it is a multiway categorical dependent variable. Thus, multinomial logistic regression was performed (47). Multinomial logistic regressions with only one independent variable were used to calculate odds ratios (ORs). Adjusted odds ratios (AORs) were computed using multinomial logistic regressions with all independent variables entered simultaneously. All analyses were performed using the SPSS statistical software Version 18.0.

\section{RESULTS}

\section{Sociodemographic Characteristics}

Sociodemographic analysis showed that there are significant differences in age, education, income, and province between ethnic minorities and Han Chinese. Gender distributions show no significant difference (Table 4).

Generally speaking, the Han Chinese have a higher socioeconomic status than ethnic minorities, with the first quartile of Zhejiang Province being equal to the fourth third of Qinghai Province, about $12,500 ¥$. The first quartile of Qinghai Province is only $3,333 ¥$, and the 2nd quartile is $6,667 ¥$. The 2nd quartile of Zhejiang Province is $20,000 ¥$ and the third quartile is $33,333 ¥$.

\section{D-P Relationships}

Respondents considered D-P relationships with primary care doctors to be similar to friendships (33.2\%), trading services $(37.8 \%)$, or other types $(29.0 \%)$. However, for large hospitals, there was a strong association with business-type (trading) D-P relationships $(50.9 \%)$, with few associating doctors in hospitals with friends $(17.3 \%)$. This general pattern was observed in both Qinghai Province and Zhejiang Province.

The main finding is the effect of ethnicity on D-P relationships. The Han Chinese perceive D-P relationships differently from ethnic minorities (Table 3 ). For primary care doctors, $63.8 \%$ of the ethnic minorities indicated having a friend relationship with their physician, but only $23.3 \%$ indicated having a trading relationship. For the Han Chinese, 29.4\% indicated a friend relationship, and $39.6 \%$ had trading relationships. However, for physicians working in big hospitals, $52.9 \%$ of the ethnic minorities indicated a friend relationship with their physicians, and $30.1 \%$ indicated trading relationships. For Han Chinese, the percentage of friend relationships was only $12.8 \%$ for physicians in big hospitals, but $53.5 \%$ indicated trading relationships.

\section{Factors Influencing D-P Relationships}

When perceiving relationships with primary care doctors, both for unadjusted OR and adjusted OR, Han Chinese are more likely to reflect trading-type or other types of relationships than friendships. However, ethnic minorities are more likely to think of the D-P relationship as a friendship than a trading relationship (Nagelkerke's $R^{2}=0.146$ ) (Table 5).

When perceiving relationships with doctors in large hospitals, this ethnic difference is also evident. Ethnic minorities' tendency to have friendly D-P relationships is consistent with lower levels of education, lower income, and provinces that are economically underdeveloped (Qinghai Province vs. Zhejiang Province) (Nagelkerke's $R^{2}=0.160$ ) (Table 6).

\section{Interactions}

When ethnicity was added to the model, the significant unadjusted OR of trading-type vs. friendship with physicians in different provinces become insignificant (primary care) or 
TABLE 4 | Sociodemographic characteristics of the sample.

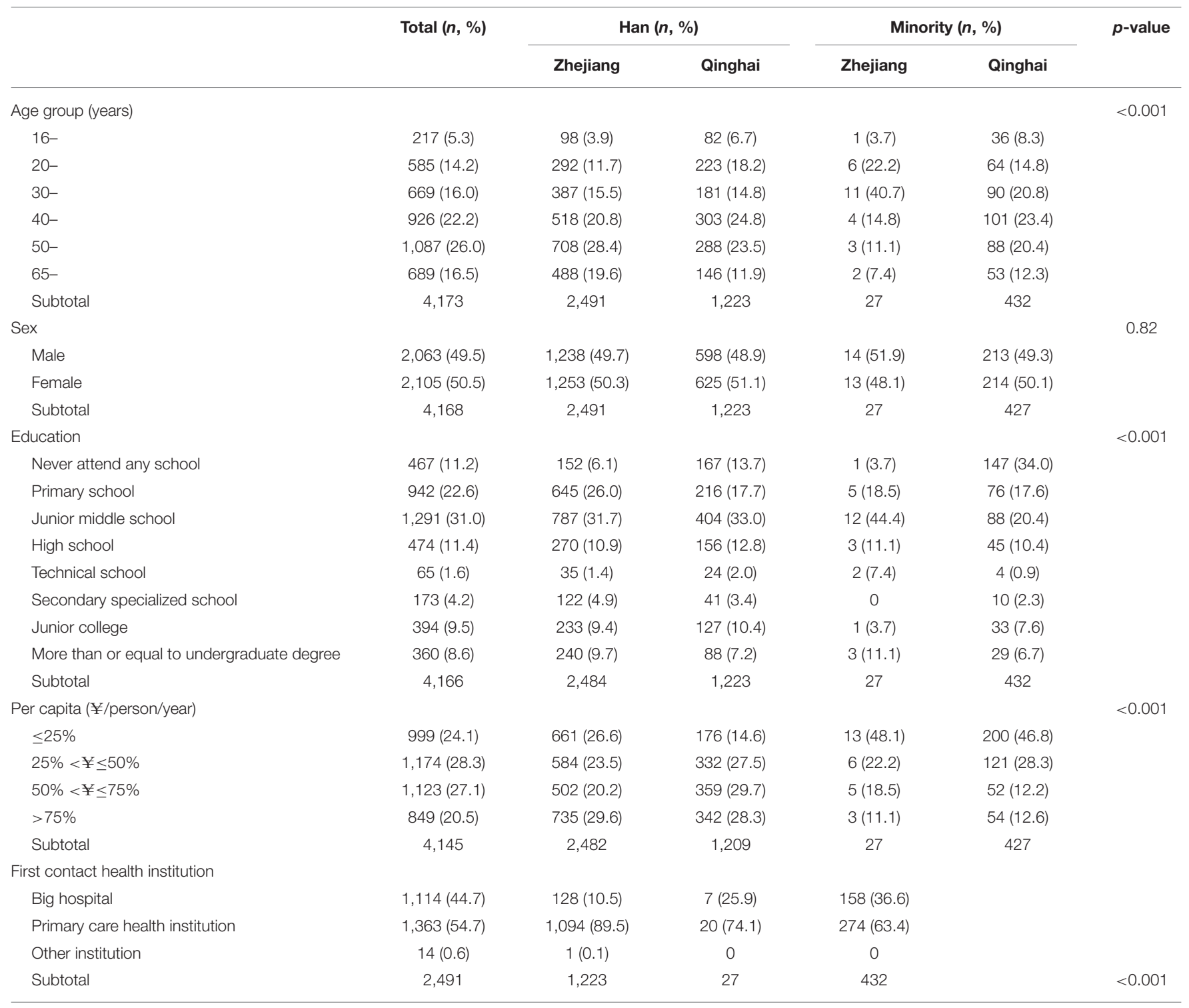

$p$-value compared with Han and Minority by $\chi^{2}$-test.

reversed (big hospital) in an adjusted OR (Tables 5, 6). To better understand the influence of ethnicity, income, and/or province on the perception of D-P relationships, we ran interaction tests for these factors. First, we tested ethnicity and income for primary care in Qinghai Province, and added gender, age, and education as predictors for different types of D-P relationships $\left(\chi^{2}=469.70, p<0.001\right.$, Nagelkerke's $\left.R^{2}=0.124\right)$ (Figure 1).

The interaction between ethnicity and income for relationships with doctors in big hospitals in Qinghai Province is also significant $\left(\chi^{2}=606.00, p<0.001\right.$, Nagelkerke's $R^{2}=0.359$ ). Ethnic minorities in Qinghai Province are more likely to perceive doctors in big hospitals as friends when they belong to a lower economic group (Figure 2).
Since minorities in Zhejiang Province are few (27 people), we tested the interaction of province and income for friend D$\mathrm{P}$ relationships in primary care institutions for Han Chinese only, showing significance $\left(\chi^{2}=374.10, p<0.001\right.$, Nagelkerke's $\left.R^{2}=0.109\right)$. Income has no influence on the type of D-P relationships with primary care doctors in Zhejiang Province. However, as economic status rises, people in Qinghai Province are less likely to have friendly D-P relationship with primary care doctors (Figure 3).

The impacts of ethnicity on D-P relationships in big hospitals is also significant $\left(\chi^{2}=256.15, p<0.001\right.$, Nagelkerke's $R^{2}=$ 0.079) (Figure 4). We compared province and ethnicity with people's first choice of health institution with two chi-square tests. The results show that people in Qinghai Province are more likely to go to a primary care institution $(82.7 \%)$, while those 
TABLE 5 | Multinomial regression models for relationship with grass-roots doctors.

\begin{tabular}{|c|c|c|}
\hline Independent variable & $\begin{array}{l}\text { Unadjusted OR with } \\
{[95 \% \mathrm{Cl}]}\end{array}$ & $\begin{array}{l}\text { Adjusted OR with } \\
{[95 \% \mathrm{Cl}]}\end{array}$ \\
\hline \multicolumn{3}{|l|}{ Age group (Reference: 65-) } \\
\hline \multicolumn{3}{|l|}{ Other types $16+$} \\
\hline & $0.600[0.402,0.895]$ & $0.645[0.408,1.020]$ \\
\hline \multicolumn{3}{|c|}{ Education (Reference: $\geq$ Undergraduate) } \\
\hline \multicolumn{3}{|l|}{ Trading/reciprocal-type } \\
\hline Never attend any school & $0.354[0.254,0.495]$ & $0.603[0.403,0.904]$ \\
\hline Primary school & $0.742[0.554,0.994]$ & $0.978[0.692,1.382]$ \\
\hline \multicolumn{3}{|l|}{ Other types } \\
\hline Never attend any school & $0.413[0.290,0.586]$ & $1.053[0.684,1.623]$ \\
\hline Primary school & $0.721[0.527,0.984]$ & $1.095[0.754,1.592]$ \\
\hline \multicolumn{3}{|l|}{ Income (Reference: quartile 4) } \\
\hline \multicolumn{3}{|l|}{ Trading/reciprocal-type } \\
\hline Quartile 1 & $0.339[0.275,0.419]$ & $0.408[0.320,0.520]$ \\
\hline Quartile 2 & $0.739[0.601,0.909]$ & $0.826[0.659,1.036]$ \\
\hline Quartile 3 & $1.633[1.309,2.039]$ & $1.673[1.323,2.116]$ \\
\hline \multicolumn{3}{|l|}{ Other types } \\
\hline Quartile 1 & $0.361[0.293,0.466]$ & $0.388[0.304,0.496]$ \\
\hline Quartile 2 & $0.519[0.418,0.644]$ & $0.567[0.447,0.721]$ \\
\hline Quartile 3 & $0.727[0.571,0.927]$ & $0.742[0.573,0.961]$ \\
\hline \multicolumn{3}{|l|}{ Province (Reference: Qinghai) } \\
\hline Trading/reciprocal-type & $1.327[1.148,1.536]$ & $1.019[0.858,1.209]$ \\
\hline Other types & $3.057[2.584,3.617]$ & $2.405[1.979,2.923]$ \\
\hline \multicolumn{3}{|l|}{ Ethnicity (Reference: Minority) } \\
\hline Trading/reciprocal-type & $3.683[2.912,4.658]$ & $2.547[1.951,3.326]$ \\
\hline Other types & $5.230[3.907,7.001]$ & $2.345[1.693,3.249]$ \\
\hline
\end{tabular}

$\mathrm{OR}$, odds ratio; $\mathrm{Cl}$, confidence interval. Reference group: friend-type.

in Zhejiang Province tend to go to big hospitals (44.5\%) $\left(\chi^{2}=\right.$ $\left.335.90, p<0.001, \mu^{2}=0.28\right)$. There is no difference between Han Chinese and ethnic minorities in regard to first contacted health institution $\left(\chi^{2}=1.03, p>0.05, \mu^{2}=0.01\right)$.

\section{DISCUSSION}

The current study advances our understanding that D-P relationships vary according to ethnicity and socioeconomic status. Ethnic minorities are most likely to perceive their physicians as friends, while Han Chinese are more likely to perceive a trading relationship with their physicians. The frequency of friendly D-P relationships is consistent with lower levels of education and income. This pattern is evident regardless of province or type of health care institution and seems to be correlated only with socioeconomic status. Ethnic minority groups have lower socioeconomic status than the Han Chinese, and Qinghai Province has a significantly lower GDP than Zhejiang Province.

\section{Courtesy Calls for Help From the Wild}

While socioeconomic status impacts D-P relationships, there is also a correlation with history and cultural transitions among these groups. The culture in which individuals live influences
TABLE 6 | Multinomial regression models for relationship with doctors in large hospital.

\begin{tabular}{lcc}
\hline Independent variable & Unadjusted OR with & Adjusted OR with \\
{$[95 \% \mathrm{Cl}]$} & {$[95 \% \mathrm{Cl}]$}
\end{tabular}

Education (Reference: $\geq$ Undergraduate)

Trading/reciprocal-type never attend any school

$0.299[0.203,0.440] \quad 0.568[0.349,0.922]$

Other types

Never attend any school $\quad 0.324[0.217,0.483] \quad 0.811[0.489,1.344]$

Primary school

$0.585[0.400,0.856] \quad 0.823[0.521,1.301]$

Income (Reference: quartile 4)

Trading/reciprocal -type vs. friends

Quartile 1

$0.272[0.213,0.347] \quad 0.387[0.290,0.516]$

Quartile 2

$0.578[0.448,0.744] \quad 0.668[0.503,0.887]$

Quartile 3

$1.464[1.090,1.967] \quad 1.461[1.065,2.004]$

Other types vs. friends

Quartile 1 quartile 2

$0.349[0.271,0.448] \quad 0.487[0.362,0.656]$

$0.636[0.474,0.854] \quad 0.582[0.432,0.785]$

Province (Reference: Qinghai)

Trading/reciprocal -type

Other types

$1.316[1.111,1.559] \quad 0.598[0.476,0.751]$

Ethnicity (Reference: Minority)

Trading/reciprocal -type

$2.327[1.929,2.807] 1.109[0.869,1.413]$

Other types

$7.335[5.819,9.247] \quad 6.931[5.206,9.226]$

$8.164[6.195,10.759] \quad 6.503[4.683,9.030]$

$\mathrm{OR}$, odds ratio; $\mathrm{Cl}$, confidence interval. Reference group: friend-type.

the way they communicate (48). As an important form of communication, the D-P relationships vary according to culture related to ethnicity. Our results are consistent with the previous Israeli D-P relationship study (5), that compared ethics, age, gender, education, income, doctor visits, and health status, finds there is a most robust difference in the D-P relationships between Arabs and Jews. Relatively more Arabs (53.8\%) than Jews (21.6\%) reported friend relationships. In Israel, Arabs compose the minority, and Jews represent the majority ethnic group $(6,377,000$ out of $8,550,000)$. The Uyghur, the second largest minority group (33.1\%) in our study, predominantly Muslim, reflect similar D-P relationships to the Arabs in the Israeli study.

The impact of ethnicity on D-P relationships in China can be interpreted in light of the Confucian saying, Courtesy calls for help from the wild (礼失而求诸野) (45). The dominant school of Chinese ethics is Confucianism. In contrast to the selffocused traditions of the West, Confucian influence on East Asian cultures leads individuals to consider others explicitly, stressing the notion that productive societies should have a relationshipand group-centered focus (49).

Confucianism considers four hierarchical relationships as the basis of society: king and subject, father and son, husband and wife, and elder and younger brother. In each of these relationships, the latter party with less power is expected to conform to the ruling of the more powerful party (50). Confucianism has been more strongly retained in rural areas of China than in urban areas. As Fei (51) noted, rural China is an acquaintance society that is regulated by village rules (51). Following this pattern, D-P relationships are more 


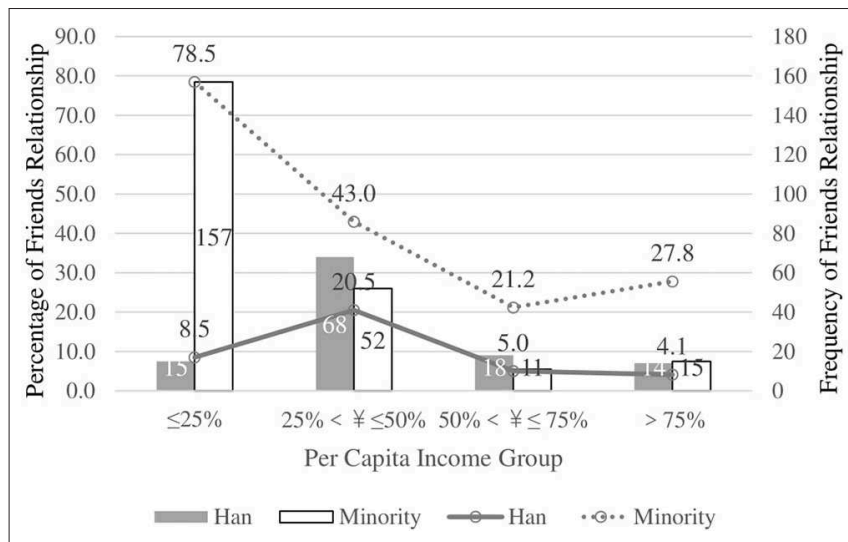

FIGURE 1 | Interaction between ethnics and income for Friends relationship with doctors in Primary Care Institution in Qinghai Province.

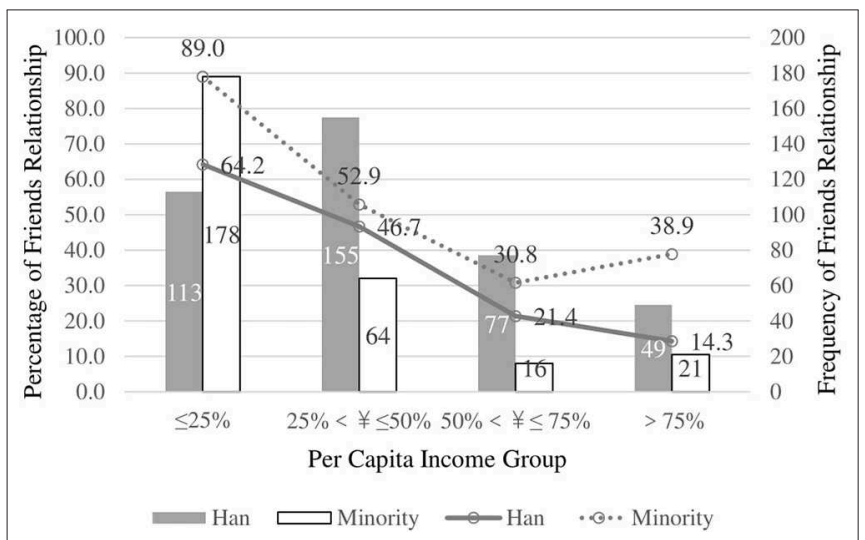

FIGURE 2 | Interaction between ethnics and income for Friends relationship with doctors in Big Hospitals in Qinghai Province.

likely to approach friend relationships in rural areas than in urban hospitals.

China has experienced significantly economic reforms. Capitalist markets have been accompanied by western culture and urbanism; as a result, traditional Confucianism has partly collapsed, especially in areas strongly influenced by economic reform, such as the eastern areas where the Han Chinese are concentrated. However, over the course of its history, predominant Chinese culture has exchanged and communicated with the surrounding ethnic minorities, who play roles of competitors, supervisors, and enhancers of Chinese culture. There is a dynamic system of interaction between Chinese central culture and the cultures of surrounded ethnic minorities. In many cases, the minority ethnic groups inherited and recreated elements of traditional Chinese culture when the central regions suffered wars, decline, and mourning. Subsequently during revitalization, the political power of the Han Chinese would learn and re-inherit these traditions from the ethnic minorities. This process is known as "seeking from the surrounding ethnic minorities when the rite was lost (of the central culture)," or courtesy calls for help from the wild.

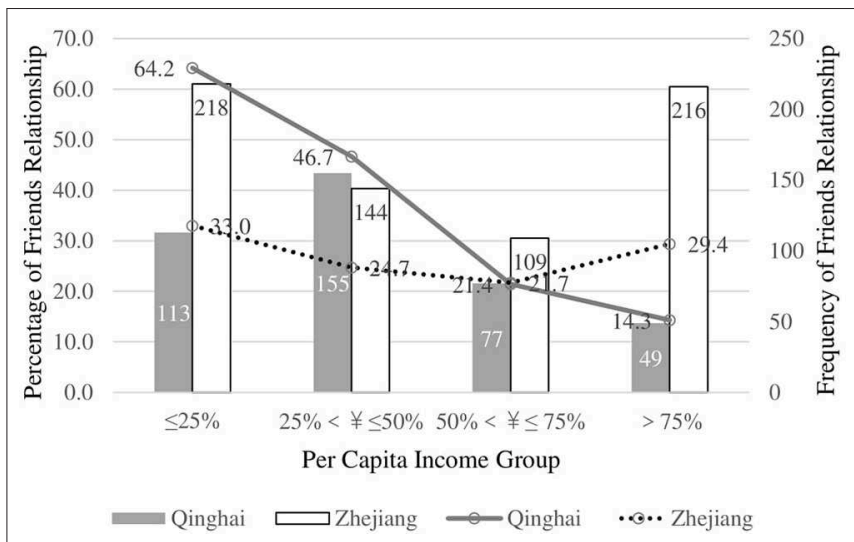

FIGURE 3 | Interaction between ethnics and income for Friends relationship with doctors in Primary Care Institution for Han Chinese.

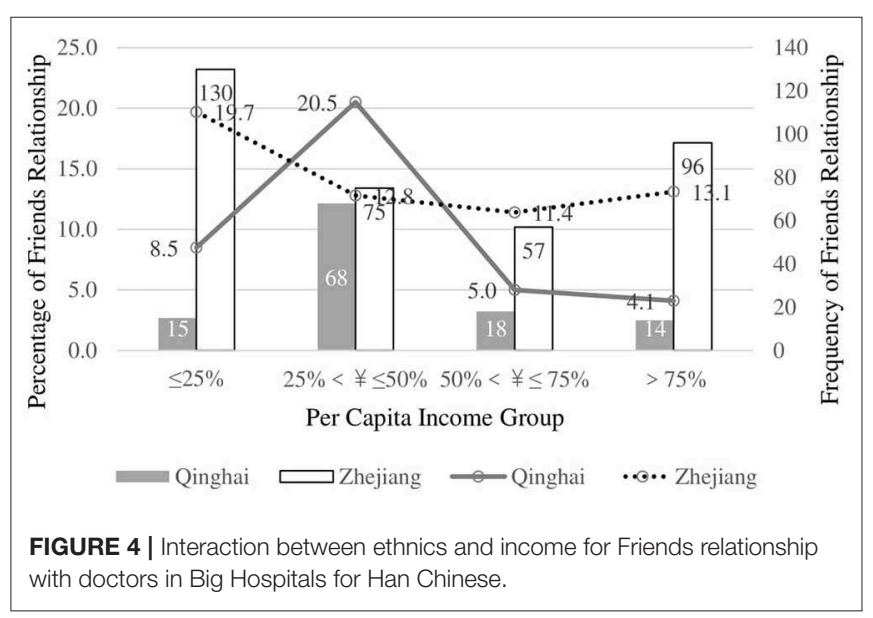

Three decades ago, contrary to current strained D-P relationships, Chinese patients trusted their doctors so much that they were unfamiliar with informed consent. What the doctor did was regarded as representing the best interests of the patient, and the doctor thought it only right to make decisions for the patient (52). However, today violence in Chinese hospitals is not uncommon. In 2015, a poll conducted by the Chinese Medical Doctor Association found that $13 \%$ of 12,600 doctors said they had been physically assaulted by their patients in the last year (53). Despite the number of lawsuits in 2016 falling by $6.7 \%$, the negative effects of individual cases was still a significant issue (54).

Because of limited modernization, the value of traditional culture in delayed market-oriented reform is significant. The pursuit of utility is increasingly displacing the efforts to retain tradition, is exacerbated by the absence of religion, psychological confusion, and the mutation of social ethics. However, due to the limited influence of modernization, Chinese western minority areas maintain relatively traditional and straightforward values and religious beliefs. Thus, they are more likely to treat the D-P relationships as friends instead of trading-relationship. 


\section{Income Gap}

As Louis Wirth suggested, urbanism brought social disorganization and individual alienation (55). It congregated "critical masses" or people to threaten the social trust. After the Second World War and the Civil War, the feudal social and political system in the western national regions not only ended, but the economic and cultural system of the former society also disintegrated. In effort to modernize, the government established a highly integrated network of organizations to undertake economic, social, and cultural organization.

Although culture and ethnicity play a major role in $\mathrm{D}-\mathrm{P}$ relationships, perceived $\mathrm{D}-\mathrm{P}$ relationships of primary care institutions also demonstrate the influence of economy. Social psychologists have demonstrated that people who strongly value money have poorer relationships (56), and money can injure social relationships (57). In our study, the friendly D-P relationships of Han Chinese in Qinghai Province are not very sensitive to income. As shown in Figure 1, however, friendly D$\mathrm{P}$ relationships among ethnic minorities in Qinghai Province decrease as income increases. Moreover, findings among Han Chinese demonstrate the power of income gaps (Figure 3). The standard deviation of income in Qinghai Province $(24,454 ¥)$ is higher than in Zhejiang Province $(21,625 ¥)$. This shows that income is not correlated with D-P relationships in Zhejiang Province. However, in Qinghai Province, lower income groups are more likely to perceive D-P relationship as friends than higher income groups. The highest group (quartile 4) is the least likely to perceive a friendly D-P relationship.

\section{Levels of Health Institution}

Given the diversity of the country, the overarching goal for Chinese public hospitals, is to recognize that different models are needed for different geographic locations and hospital settings (41). This is in contrast to hospital reform in USA and Europe, which focus on cost control. Specific management plans for service stations, health hospitals, and big hospitals should be different.

Chinese big hospitals are concentrated in cities but the primary care institutions are scattered around the rural areas, which is just consistent with the proportion of Han physicians to ethnic minority physicians, especially in ethnic autonomous prefectures in Qinghai. In our interview with a local health official, we have learnt that the ethnic minority village doctors are $<10 \%$ in areas where Han Chinese major live. However, the ethnic minority village doctors account for $90 \%$ of the village doctors in ethnic autonomous prefectures. In township health center, there are still about $60 \%$ physicians are ethnic minorities. As a result, patients have a higher opportunity to contact with ethnic minority physicians in Qinghai ethnic minority rural areas than in big cities. The ethnic minority physicians in rural areas, as we have discussed above, who have preserved Chinese traditional personality of warm and friendly, are more salient than in urban Han Chinese physicians. Thus, they were more likely to be perceived as friends by their patients than big hospital physicians.

The proportion of ethnic minority residents in rural areas is also more significant than the index of urban areas. Researchers have demonstrated that the people who live in more densely populated areas tend to report less satisfied interpersonal communication because high population density implied worse resources scarcity and more furious competition (58-60). However, the population density in rural areas is less than in urban cities. Thus, ethnic minority residents have more opportunity to know about each other, especially their ethnic minority physicians.

According to the social psychological theory, similarity, familiarity, proximity, and to be liked is the basic rules in interpersonal attraction (61). Similarity indicated that people tend to make friends who are similar to themselves in demographics and characteristics, in which ethnicity is a very important factor. Perceived similarity results in the assumption that people have more in common, facilitating warmer, more comfortable interactions, all of which facilitate attraction. People are more likely to make friends with people who has the same race or ethnicity with them (62). Thus, the distribution of ethnicity minorities and Han Chinese of physicians in rural and urban areas could explain patients' preference of perceived D-P relationships among different levels of health institutions: patients like to make friends with ethnic minority physicians who share the same characteristics with themselves in rural areas, but it is difficult for patients to make friends with Han Chinese physicians with significant western or modern characteristics.

As masters of medical technology, doctors are the medical experts. Thus, there is a power relationship between doctors and patients according to social power theory $(63,64)$, including expert power, referent power, and even legitimate power (65, 66). Powerful people usually stereotype others to save cognitive resources (67), control others (68), and objectify other people (69). Thus, doctors with higher technical abilities (usually found in bigger hospitals) take a leading trading-type role when they communicate with patients. People believe the best way to enhance effectiveness is to fit the right kind of leaders to the situations they face (70). As a service occupation, medical practice provides services of different grades to meet patient expectations and results in the best service effect.

Realizing these facts, the Chinese State Council (71) issued a statement to clarify the function of medical institutions at all levels, indicating that medical and health service at hospitals and primary care institutions should be liable for the treatment of different diseases. Urban tertiary hospitals provide services for critical and complex diseases. Secondary hospitals mainly provide treatment for common diseases, as well as the immediate treatment of the patients with acute, severe, or complicated diseases. Primary care institutions, rehabilitation hospitals, and nursing homes provide treatment, rehabilitation, nursing services for stable patients with chronic diseases, the elderly, and patients with advanced cancer (72).The cross-sectional design of our study makes inferences of causal relationships between indicators of D-P relationships and associated factors impossible. Our study site of developed province (Zhejiang) has a deeper degree of globalization, modernization, and urbanization than undeveloped province (Qinghai) because of the geographic and socioeconomic conditions. Globalization, modernization, and urbanization has broken up the Chinese traditional culture. As a result, they provided conditions for ethnic minorities to 
preserved more friendly relationship with physicians than Han Chinese. The effect which globalization has played may be as same as higher socioeconomic status, higher income, and higher hierarchy of hospitals. WHO has proposed "health policies should be culturally appropriate" as an approach of many other public health studies (73-76). Globalization could explain why big hospitals, most of which are mainly tertiary hospitals in the cities, are more likely to perceive trading type relationship, but it could not explain why ethnic minorities more likely to perceive friendly relationship. Only "courtesy calls for help from the wild" and globalization are considered at the same time, can they be explained together about the opposite perception of D-P relationship between ethnic minorities and Han Chinese. Further studies should adopt qualitative research in anthropology, to explore the impacts of Chinese Confucian culture and the tide of globalization.

\section{CONCLUSION}

The primary contribution of this research is the finding that D-P relationships differ for Han Chinese and other ethnic minorities. Ethnic minorities are most likely to perceive their physicians as friends, while Han Chinese are likely to have a trading relationship with their physicians. Compared to Han Chinese, ethnic minorities retain Confucian ideals, then which results in a focus on friendly relationships and respect of others. This discrepancy is more obvious according to the hierarchy of health institutions. The Han Chinese have experienced a higher degree of globalization, economic reform, and adoption of western values, which has influenced their culture and lead to a tendency to view the D-P relationships as

\section{REFERENCES}

1. He AJ. The doctor-patient relationship, defensive medicine and overprescription in Chinese public hospitals: evidence from a crosssectional survey in Shenzhen city. Soc Sci Med. (2014) 123:64-71. doi: 10.1016/j.socscimed.2014.10.055

2. $\mathrm{Xu}$ W. Violence against doctors in China. Lancet. (2014) 384:745. doi: 10.1016/S0140-6736(14)61438-0

3. Sun N, Rau P-LP. Barriers to improve physician-patient communication in a primary care setting: perspectives of Chinese physicians. Health Psychol Behav Med. (2017) 5:166-76. doi: 10.1080/21642850.2017.1286498

4. Tso-Kew M. The Chun Tsew, with the Tso Chuen. In: Legge J, Editor. The Chinese Classics. Taipei: SMC Publishing Inc. (1991). p. 372-4.

5. Magnezi R, Bergman LC, Urowitz S. Would your patient prefer to be considered your friend? Patient preferences in physician relationships. Health Educ Behav. (2015) 42:210-9. doi: 10.1177/1090198114 547814

6. Fu R, Zuo T, Lenihan E. Discourses matter: Chinese ethnic minorities in sustainable development. Sustain Develop. (2011) 19:359-68. doi: $10.1002 /$ sd.436

7. Russo J. Recovery, Mental Health and Inequality. Chinese Ethnic Minorities as Mental Health Service Users. London; New York, NY: Routledge (2017). doi: 10.1080/09687599.2017.1414303

8. Yao J, Yang L. Perceived prejudice and the mental health of chinese ethnic minority college students: the chain mediating effect of ethnic identity and hope. Front. Psychol. (2017) 8:1167. doi: 10.3389/fpsyg.2017. 01167 transactional. The bigger hospitals in urban areas also increase this trend. The awareness of these changes and trends in $\mathrm{D}-\mathrm{P}$ relationships increases an understanding of the increase in dissatisfaction and violence that are presented in today's medical field.

\section{DATA AVAILABILITY STATEMENT}

The raw data supporting the conclusions of this manuscript will be made available by the authors, without undue reservation, to any qualified researcher.

\section{ETHICS STATEMENT}

The studies involving human participants were reviewed and approved by the Ethics Committee of Zhejiang University. Written informed consent to participate in this study was provided by the participants' legal guardian/next of kin.

\section{AUTHOR CONTRIBUTIONS}

QY and HD: study concept and design, and Obtained funding. QY: drafting of the manuscript. QY and MY: statistical analysis. HD: study supervision. All authors critical revision of the manuscript for important intellectual content, acquisition, analysis, and interpretation of data.

\section{FUNDING}

This study was funded by National Natural Science Foundation of China (71603233 and 71573229).
9. The State Council P.R. China. Ethnic Groups in China. (2014). Available online at: http://english.gov.cn/archive/china_abc/2014/08/27/content_ 281474983873388.htm (accessed July 23, 2018).

10. [SCOC] and [DPES]. Statistics of 2010 National Census. Beijing (in Chinese): China Statistical Press (2012).

11. Zhong Y. A Cross- cultural research on the ethnic well-being: In the viewpoint of Han, Hui and Tibetan along the Daxia River. (Ph.D.). Lanzhou University, Lanzhou, China (2016).

12. Xie J. The Characteristic and Relationship between Physical Self, Academic Self and Social Self with Depression in the Freshman of the Yi, Bai, Han Nationality. Chongqing: Army Medical University of P.R. China (2011).

13. Hofstede G. Organizations and Cultures: Software of the Mind. New York, NY: McGrawHill (1991).

14. Hunt SD, Vitell SJ. The General Theory of Marketing Ethics: A Retrospective and Revision. Ethics in Marketing. Homewood, IL: Irwin Inc. (1993). p. 775-84.

15. Hofstede G. Culture's Consequences: Comparing Values, Behaviors, Institutions and Organizations across Nations. Thousand Oaks, CA: Sage Publications (2003).

16. Hofstede G, Bond MH. The Confucius connection: from cultural roots to economic growth. Org Dyn. (1988) 16:5-21. doi: 10.1016/0090-2616(88)90009-5

17. Chiu CCH, Ting KF, Tso GKF, Cai H. A comparison of occupational values between capitalist Hong Kong and socialist Guangzhou. Econ Develop Cultural Change. (1998) 46:749-70. doi: 10.1086/ 452372

18. Harvey B. "Graceful merchants": a contemporary view of Chinese business ethics. J Bus Ethics. (1999) 20:85-92. doi: 10.1023/A:1005795117923 
19. Chan RYK, Cheng LTW, Szeto RWF. The dynamics of guanxi and ethics for Chinese executives. J Bus Ethics. (2002) 41:327-36. doi: 10.1023/A:1021230831161

20. Blumenthal D, Hsiao W. Lessons from the East-China's rapidly evolving health care system. $N$ Engl J Med. (2015) 372:1281-5. doi: 10.1056/NEJMp1410425

21. Whitcomb LL, Erdener CB, Li C. Business ethical values in China and the U.S. J Bus Ethics. (1998) 17:839-52. doi: 10.1023/A:1005793424492

22. Su C, Sirgy MJ, Littlefield JE. Is guanxi orientation bad, ethically speaking? A study of Chinese enterprises. J Bus Ethics. (2003) 44:303-12. doi: 10.1023/A:1023696619286

23. Fei HT, Chang CI. Earthbound China. Chicago, IL: University of Chicago Press (1945).

24. Celarent B. Earthbound China. Am J Soc. (2013) 118:1153-60. doi: $10.1086 / 669921$

25. Axelrod DA, Goold SD. Maintaining trust in the surgeon-patient relationship - challenges for the new millennium. Archiv Surg. (2000) 135:55-61. doi: 10.1001/archsurg.135.1.55

26. Rada RT. The health-care revolution: from patent to client to Customer. Psychosomatics. (1986) 27:276-9. doi: 10.1016/S0033-3182(86)72702-3

27. Deber RB, Kraetschmer N, Urowitz S, Sharpe N. Patient, consumer, client, or customer: what do people want to be called? Health Expect. (2005) 8:345-51. doi: 10.1111/j.1369-7625.2005.00352.x

28. Krugman P. Patients are not consumers. The New York Times (2004).

29. World Health Orgnization. What is People-Centred Health Care? (2018). Available online at: http://www.wpro.who.int/health_services/people_at_the_ centre_of_care/definition/en/ (accessed August 10, 2018).

30. Bakker DA, Fitch MI, Gray R, Reed E, Bennett J. Patient-health care provider communication during chemotherapy treatment: the perspectives of women with breast cancer. Patient Educ Counsel. (2001) 43:61-71. doi: 10.1016/S0738-3991(00)00147-6

31. Merckaert I, Libert Y, Razavi D. Being known: patients' perspectives of the dynamics of human connection in cancer care. Psycho Oncol. (2005) 14:899900. doi: 10.1002/pon.966

32. Salander P, Henriksson R. Severely diseased lung cancer patients narrate the importance of being included in a helping relationship. Lung Cancer. (2005) 50:155-62. doi: 10.1016/j.lungcan.2005.05.023

33. Thorne SE, Kuo M, Armstrong EA, McPherson G, Harris SR, Hislop TG. 'Being known': Patients' perspectives of the dynamics of human connection in cancer care. Psycho Oncol. (2005) 14:887-98. doi: 10.1002/pon.945

34. Baskett TF. What women want: don't call us clients,and we prefer female doctors. J Obstetr Gynaecol Canada. (2002) 24:572-4. doi: 10.1016/S1701-2163(16)31060-X

35. Denning AS, Tuttle LK, Bryant VJ, Walker SP, Higgins JR. Ascertaining women's choice of title during pregnancy and childbirth. Austr N Z J Obstetr Gynaecol. (2002) 42:125-9. doi: 10.1111/j.0004-8666.2002.00125.x

36. Wittich AC, Junnila J, Buller J. Would your patients prefer to be your clients? J Am Osteopathic Assoc. (2003) 103:485-7. doi: 10.7556/jaoa.2003.103.10.485

37. Lyratzopoulos G, Elliott M, Barbiere JM, Henderson A, Staetsky L, Paddison C, et al. Understanding ethnic and other socio-demographic differences in patient experience of primary care: evidence from the English General Practice Patient Survey. BMJ Qual Saf. (2012) 21:21-9. doi: 10.1136/bmjqs-2011-000088

38. Gibert SH, DeGrazia D, Danis M. Ethics of patient activation: exploring its relation to personal responsibility, autonomy and health disparities. J Med Ethics. (2017) 43:670-5. doi: 10.1136/medethics-2017-104260

39. Starfield B, Shi L, Macinko J. Contribution of primary care to health systems and health. Milbank Q. (2005) 83:457-502. doi: 10.1111/j.1468-0009.2005.00409.x

40. Starfield B. Primary Care: Balancing Health Needs, Services, and Technology. New York, NY: Oxford University Press (1998).

41. Barber SL, Borowitz M, Bekedam H, Ma J. The hospital of the future in China: China's reform of public hospitals and trends from industrialized countries. Health Policy Plan. (2014) 29:367. doi: 10.1093/heapol/ czt023

42. Liu L, Xie Z, Qiu Z, Zhang T. Doctor-patient relationship in different level hospitals and influencing factors from doctor side (in Chinese). Med Philos. (2009) 30:30-6.
43. Cheng J, Zhang Y, Zhang L, Lu SR. Survey and analysis of the doctor?patient relationship different level general hospitals (in Chinese). Chinese Med Ethics. (2010) 23:20-83.

44. Wang W, Wu Z, Yue W, Qi Y, Zhou J, Xiong Y, et al. Studying on the status of doctor-patient relationship in different hospitals of Henan and its influencing factors (in Chinese). Chinese Health Serv Manage. (2016) 19-21, 55.

45. Pan, K. (1938). Treatise on literature. In: Dubs HH, editor. The History of the Former Han Dynasty. Baltimore, MD: Waverly.

46. Deng Y, Liu S, Cai J, Lu X. Spatial pattern and its evolution of Chinese provincial population and empirical study. Acta Geograph Sin. (2014) 69:1473-86.

47. Friedman J, Hastie T, Tibshirani R. Regularization paths for generalized linear models via coordinate descent. J Stat Softw. (2010) 33:1-22. doi: $10.18637 /$ jss.v033.i01

48. Gudykunst WB, Ting-Toomey S. Chapter 1: Communication in personal relationshps across cultures: an introduction. In: Gudykunst WB, TingToomey S, Nishida T, editors. Communication in Personal Relationships Across Cultures. Thousand Oaks, CA: SAGE Publications (1996). p. 3.

49. Nisbett RE, Peng K, Choi I, Norenzayan A. Culture and systems of thought: comparison of holistic and analytic cognition. Psikhologicheskii Zhurnal. (2011) 32:55-86.

50. Zhong CB, Magee JC, Maddux WW, Galinsky AD. Power, culture, and action: Considerations in the expression and enactment of power in East Asian and Western societies. In: Chen Y, editor. National Culture and Groups (Research on Managing Groups and Teams. Vol. 9. Bingley: Emerald Group Publishing Limited (1996). p. 53-73. doi: 10.1016/S1534-0856(06) 09003-7

51. Fei X. Peasant Life in China: A Field Study of Country Life in the Yangtze Valley. London: Routledge \& Kegan Paul (1962).

52. Cong Y. Doctor-family-patient relationship: the Chinese paradigm of informed consent. J Med Philos. (2004) 29:149-78. doi: 10.1076/jmep.29.2.149.31506

53. An. Chinese Doctors: What We Need is Respect and Understanding. (2015). Available online at: http://news.xinhuanet.com/english/2015-06/17/c 134334805.htm (accessed April 17, 2017).

54. Yin C. Medical Dispute Cases See Significant Decline. (2017). Available online at: http://www.chinadaily.com.cn/china/2017-02/24/content_28332274.htm (accessed April 17, 2017).

55. Wirth L. Urbanism as a Way of Life. In K. G. Specht, editor. Soziologische Forschung in Unserer Zeit: Ein Sammelwerk Leopold von Wiese zum 75. Geburtstag. Wiesbaden: VS Verlag für Sozialwissenschaften (1951). p. 320-35.

56. Kasser T, Ryan RM. A dark side of the American dream: correlates of financial success as a central life aspiration. J Person Soc Psychol. (1993) 65:410. doi: 10.1037/0022-3514.65.2.410

57. Zhou X, Yang Q, Hu X. When money meets morality: human universals and cultural differences. Psych J. (2018) 7:105-6. doi: 10.1002/pchj.213

58. Levy L, Herzog AN. Effects of population density and crowding on health on health and social adapation in the Netherlands. J Health Soc Behav. (1974) 15:228-40. doi: 10.2307/2137023

59. Kirmeyer SL. Urban density and pathology a review of research. Environ Behav. (1978) 10:247-69. doi: 10.1177/0013916578102006

60. Jain U. Effects of population density and resources on the feeling of crowding and personal space. J Soc Psychol. (1987) 127:331-8. doi: 10.1080/00224545.1987.9713699

61. Schneide FW, Gruman JA, Coutts LM. Applied Social Psychology: Understand and Addressing Social and Practical Problems. Thousand Oaks, CA: SAGE Publications, Inc. (2011).

62. Kao G, Joyner K. Do race and ethnicity matter among friends? Sociol Q. (2004) 45:557-73. doi: 10.1111/j.1533-8525.2004.tb02303.x

63. French J, Raven B, Cartwright D. Studies in Social Power. Ann Arbor, MI: University of Michigan Press (1959). p. 150-67.

64. French J, Raven B. The Bases if Social Power. New York, NY: Studies in social Power Univer of Michigan Institute for Social Research (1968). p. 150-67.

65. van Marle HJC. The patient rules; the power of transference in the doctor-patient relationship. Nederlands Tijdschrift Voor Geneeskunde. (2016) 160:D1219.

66. Lyngstad I. Legitimate, expert and referent power in physical education. Sport Educ Soc. (2017) 22:1-11. doi: 10.1080/13573322.2015.1116442 
67. Fiske ST. Controlling other people: the impact of power on stereotyping. Am Psychol. (1993) 48:621. doi: 10.1037/0003-066X.48.6.621

68. Fast NJ, Gruenfeld DH, Sivanathan N, Galinsky AD. Illusory control: a generative force behind power's far-reaching effects. Psychol Sci. (2009) 20:502-8. doi: 10.1111/j.1467-9280.2009.02311.x

69. Gruenfeld DH, Inesi ME, Magee JC, Galinsky AD. Power and the objectification of social targets. J Personal Soc Psychol. (2008) 95:111-27. doi: 10.1037/0022-3514.95.1.111

70. George JM, Jones GR. Understanding and Managing Organizational Behavior. Los Alamitos, CA: Delta Publishing Company (2006).

71. Chinese State Council. Guiding opinions of The General Office of the State Council on promoting the construction of a hierarchical diagnosis and treatment system. Beijing: Bulletin of the State Council of the People's Republic of China (2015).

72. Information Office of the State Council. The Guidance of Promoting Referral System Construction Provided by the General Office of the State Council. (in Chinese). Beijing: Information Office of the State Council (2015).

73. Johnstone MJ, Kanitsaki O. Engaging patients as safety partners: some considerations for ensuring a culturally and linguistically appropriate approach. Health Policy. (2009) 90:1-7. doi: 10.1016/j.healthpol.2008.08.007

74. Johnson CL, Dickerson DL, Satter DE, Wallace SP. American Indians and Behavioral Health Issuesin California: Implicationsfor Culturally
Appropriate Treatment. Ucla Center for Health Policy Research (2012).

75. Levin-Zamir D, Badarne S, Najami M, Gan NS, Poraz I, Shapira $\mathrm{M}$, et al. The use of focus groups as a basis for planning and implementing culturally appropriate health promotion among people with diabetes in the Arab community. Glob Health Promot. (2015) 2015:1-9. doi: $10.1177 / 1757975914548200$

76. Guerra-Reyes L. Implementing a culturally appropriate birthing policy: ethnographic analysis of the experiences of skilled birth attendants in Peru. J Pub Health Policy. (2016) 37:353-68. doi: 10.1057/jphp.2016.19

Conflict of Interest: The authors declare that the research was conducted in the absence of any commercial or financial relationships that could be construed as a potential conflict of interest.

Copyright $\odot 2019$ Yang, Zhang, Yu, Hu, Gu, Sun, Zhen, Gu, Huang, Wei, Zeng and Dong. This is an open-access article distributed under the terms of the Creative Commons Attribution License (CC BY). The use, distribution or reproduction in other forums is permitted, provided the original author(s) and the copyright owner(s) are credited and that the original publication in this journal is cited, in accordance with accepted academic practice. No use, distribution or reproduction is permitted which does not comply with these terms. 